\title{
Okul Öncesi Çocuklarda Fiziksel Uygunlukla Doğum Ağırlığı, Gelir Düzeyi ve Okul Süresi Arasındaki İlişkinin İncelenmesi*
}

\section{Investigation of the Relationship Between Physical Fitness And Birth Weight, Income Level And School Period in Preschool Children}

Halil Alkan, ${ }^{\text {a** }}$ Akmer Mutlu ${ }^{\mathrm{b}}$

${ }^{a}$ Dr., Muş Alparslan Üniversitesi, Sağlık Yüksekokulu, Fizyoterapi ve Rehabilitasyon Bölümü, Diyarbakır Yolu 7. km, Merkez/Muş. Türkiye. ORCID: 0000-0001-6895-2495.

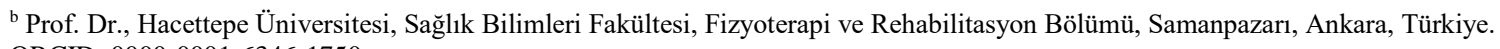
ORCID: 0000-0001-6346-1750

\section{MAKALE BİLGİSİ \\ Makale Geçmişi: \\ Başvuru tarihi: 01 Şubat 2019 \\ Düzeltme tarihi: 02 Şubat 2019 \\ Kabul tarihi: 14 Şubat 2019}

Anahtar Kelimeler:

Doğum ağırlığı

Gelir düzeyi

Fiziksel uygunluk

\section{ARTICLE INFO}

Article history:

Received 01 February 2019

Received in revised form 02 February 2019

Accepted 14 February 2019

\section{Keywords:}

Birth weight

Income level

Physical fitness
ÖZ

Bu çalışmadaki amacımız okul öncesi çocukların doğum ağırlığının, sosyo-ekonomik durumun ve okul süresinin fiziksel uygunlukla ilişkisini araştırmaktır. Çalışma Muş İl Milli Eğitim Bakanlığı'na bağlı okulların ana sınıflarında bulunan, 4-6 yaş aralığındaki 212 sağlıklı çocuklarda yapıldı. Çocukların sosyodemografik ve doğum özellikleri kaydedildikten sonra çocukların fiziksel uygunluklarını değerlendirmek için bu yaş aralığına özel geliştirilen PREschool Physical FITness (PREFIT) test bataryası kullanıldı. Çocukların okulda geçirdikleri toplam dönem sayısı kaydedildi. Çocukların fiziksel uygunlukları ile okuldaki dönem süresi arasında ilişki bulunmuştur $(\mathrm{p}<0.05)$. Okul öncesi çocuklarda doğum ağırlığının ve ailenin gelir düzeyinin çocukların fiziksel uygunluklarını etkilemediği bulunmasına rağmen, okulda geçirilen sürenin artmasıyla çocukların fiziksel uygunlukları artmaktadır.

\section{A B S T R A C T}

Our aim of this study is to investigate the relationship between birth weight, socio-economic status and school environment with physical fitness in preschool children.The study was carried out in 212 healthy children aged 4-6 years. PREschool Physical FITness (PREFIT) test battery developed specifically for this age range was used to evaluate the physical fitness of children. The total number of school terms that children spent at school was recorded. The statistical relationship between the physical fitness of children and the duration of school terms was found $(\mathrm{p}<0.05)$. In preschool children, although the birth weight and the family income level do not affect the physical fitness of children, the physical fitness of children increases with the increasing of their school term period.

*Bu çalışma birinci yazarın 2019 yılında Prof. Dr. Akmer Mutlu danışmanlığında Hacettepe Üniversites, Sağlık BilimleriEnstitüsü, Fizik Tedavi ve Rehabilitasyon Anabilimdalı'nda hazırladığı "Okul Öncesi Dönemdeki Çocukların Nörolojik Durumları, Gelişimsel Parametreleri ve Fiziksel Uygunlukları Arasındaki İlişkinin İncelenmesi” adlı tezden türetilmiştir.

** Sorumlu yazar/Corresponding author

e-posta: fzthalilalkan@hotmail.com 



\section{Giriş}

Fiziksel uygunluk seviyesi erken yaşlarda sağlığın güçlü bir göstergesi olmakla birlikte fiziksel aktivite de fiziksel uygunluğun ana belirleyicisidir (Ortega, Ruiz, Castillo, \& Sjostrom, 2008). Kişiye özel olan fiziksel uygunluk durumu, kassal kuvvet ve dayanıklılık, kardiyovasküler dayanıklılık, esneklik ve vücut kompozisyonu kısmı sağlıkla ilişsili iken; koordinasyon, çeviklik, güç, denge, hız ve reaksiyon zamanı ise performansla ilişkili kısmı kapsamaktadır (Thompson, Arena, Riebe, \& Pescatello, 2013). Sağlıkla ilişkili fiziksel uygunluk, fiziksel aktivite tarafindan etkilenen vücut sistemlerinin fizyolojik kapasitesi olarak da ifade edilmektedir.

Okul öncesi dönemdeki çocuklarda fiziksel aktivite seviyesi kardiovasküler risklerin belirleyicisi olmakla birlikte aerobik kapasitenin gelişiminde pozitif yönde ilişkisi olduğu bildirilmektedir (Lopes, Rodrigues, Maia, \& Malina, 2011). Başka bir raporda 6 yaş üzerindeki çocuk ve adölasanlarda düşük kas gücü ve düşük kardiopulmoner uygunluk düşük kemik yoğunluğu, metabolik risk faktörleri ve kardiovasküler hastalıklarla ilişkili olduğu vurgulanmaktadır (Smith et al., 2014). Çocuklarda düzenli fiziksel aktivite, kalp-damar sistemi dayanıklılığını ve kassal uygunluğu artırmakta, kemik sağlığını, kardiyovasküler uygunluğu ve vücut kompozisyonunu geliştirmekte, depresyonu azaltmaktadır. Bununla birlikte düzenli olarak fiziksel aktiviteye katılan çocukların yetişkinlikte daha sağlıklı olma olasılıkları yüksektir (Health \& Services, 2008). Sonuç olarak çocuklarda fiziksel aktivitenin sağlık açısından faydalı etkileri ve sedanter yaşam biçiminin zararlı etkileri göz önüne alındığında fiziksel uygunluk düzeyi araştırmacılar için popüler hale gelmektedir (Kelly, 2000).

Literatüre bakıldığında okul dönemi çocuklarda doğum ağırlığının uzun dönemde fiziksel uygunluk üzerine etkisini (Moura-Dos-Santos et al., 2013), sosyo-ekonomik yapının fiziksel uygunluk ve spor performans seviyeleri üzerine etkisini (Goslin \& Burden, 1986; Malina, Bouchard, \& BarOr, 2004) ve okul ortamının fiziksel uygunlukla ilişkisini ortaya koyan çalışmalar bulunmasına rağmen (Christodoulos, Flouris, \& Tokmakidis, 2006; Delidou, Matsouka, \& Nikolaidis, 2016); okul öncesi çocuklarda konu ile ilgili çalışmalara rastlanılmamıştır. $\mathrm{Bu}$ nedenle bu çalışmadaki amacımız okul öncesi çocuklarda doğum ağırlığı ve ailenin gelir düzeyinin fiziksel uygunluk üzerine etkisinin yanı sıra; okuldaki dönem süresiyle ilişkisini incelemektir.

\section{Yöntem}

\subsection{Bireyler}

Okul öncesi çocuklarda doğum ağırlığı ve ailenin gelir düzeyinin fiziksel uygunluk üzerine etkisinin yanı sıra; okuldaki dönem süresiyle ilişkisini incelemek amacıyla yapılan çalışma, Muş İl Milli Eğitim Bakanlığı'na bağlı okulların anasınıflarında 4-6 yaş aralığındaki çocuklarda yapıldı. Çalışmaya katılacak kişi sayısı Hacettepe Üniversitesi Tıp Fakültesi Biyoistatistik Anabilim Dalı'na başvurulurak PASS 11.0 (Power Analysis and Sample Size) yazılımı ile $\% 90$ güç, $\% 5$ yanılma payı olacak şekilde belirlendi ve toplam 212 sağlıklı çocuklar çalışmaya dahil edildi.

Çalışmanın yapılabilmesi için Muş Alparslan Üniversitesi, Bilimsel Araştırma ve Yayın Etiği Kurulu tarafından E13931 sayılı ve 2 numaralı karar ile 29/11/2017 tarihinde etik kurul izni, ve 29/12/2017-8822 tarih ve sayısı ile de Muş İl Valiliği'ne bağlı, İl Milli Eğitim Müdürlüğü'nden izin alındı. Basit rastgele yöntem ile okullar seçildikten sonra ŞubatHaziran 2018 tarihleri arasında aileler ve çocuklar ile okullarda toplantı yapılarak çalışma hakkında bilgilendirildikten sonra gönüllü olanlar çalışmaya dahil edildi.

\section{2. Ölçümler}

Muş İl Milli Eğitim'e bağlı okulların anasınıflarında gerçekleştirilen çalışmamıza 4-6 yaş aralığındaki çocukların sosyodemografik özellikleri annelerle yüz yüze görüşülerek kaydedildi. Çocukların fiziksel uygunluk düzeyini belirlemek için bu yaş aralığına özel geliştirilen PREFIT Test Bataryası kullanıldı. Her bir çocuk değerlendirmeye sırasıyla alındı ve değerlendirme süresi yaklaşık $90 \mathrm{dk}$ sürdü. Ölçümler pediatrik rehabilitasyon alanında 5 yıllık bir tecrübesi olan Uzm. Fizyoterapist tarafindan yapıldı. Değerlendirmeler tek seferde bir kez yapıldı.

\subsubsection{Demografik bilgiler}

Çalışmaya katılan çocuklar ölçüm testlerinde önce sosyodemografik ve klinik özelliklerini içeren form ailelerden alınan bilgiler doğrultusunda dolduruldu. Bu form içerisinde çocuğun yaşı (ay olarak), cinsiyeti, doğum ağırlığ (Düşük:<2500gr, Normal:2500-4000gr, Yüksek>4000gr), ailenin aylık geliri (Düşük gelir: $<2000 \mathrm{TL}$, Orta gelir:20004000TL, Yüksek gelir>4000TL), evdeki çocuk sayısı, çocuğun kaç dönemdir okula gittiği sorgulanarak kaydedildi.

\subsubsection{Fiziksel uygunluğun değerlendirilmesi}

Çocukların fiziksel uygunluklarını belirlemek için okul öncesi yaş aralığına özel Avrupada geliştirilen PREFIT Test Bataryası kullanılmıştır. Okul öncesi dönemdeki çocuklarda kullanılan bu bataryanın kolay uygulanabilen, güvenilir bir yöntem olduğu belirtilmektedir (Cadenas-Sanchez et al., 2016; Kolimechkov, 2017; Ortega et al., 2015). Bu test bataryası boy uzunluğu, kilo, bel çevresi, 20m mekik koşu testi, el kavrama kuvveti testi, uzun atlama, 4x10m koşu testi ve tek bacak üzerinde durma testlerinden oluşmaktadır (Cadenas-Sanchez et al., 2016; Kolimechkov, 2017; Martinez-Tellez et al., 2016; Ortega et al., 2015).

\subsubsection{Antropometrik özellikler}

Çocukların ağırlıkları elektronik bir terazi ile kg olarak ölçülürken, boyları cm cinsinden kaydedildi. Ölçüm sırasında çocukların yalın ayak, minimal giysili olmaları 
istendi. VKI'leri $\mathrm{kg} / \mathrm{m}^{2}$ formülü ile hesaplandı (CadenasSanchez et al., 2016; Martinez-Tellez et al., 2016). Bütün ölçümler iki kez yapılarak istatistiksel analiz için ortalamaları alındı.

\subsubsection{Kardiorespiratuar uygunluk}

Kardiorespiratuar uygunluk, fiziksel aktivite süresince kaslara kardiovasküler ve respiratuar sistemin besin ve oksijen taşıma kapasitesini yansıtmaktadır (de Rezende, Lopes, Rey-Lopez, Matsudo, \& Luiz, 2014). Literatürde aerobik güç, aerobik kapasite, fiziksel iş kapasitesi, maksimal oksijen tüketimi gibi terimlerle de ifade edilmektedir (Ortega et al., 2015). Okul öncesi çocuklarda kardiorespiratuar uygunluğu değerlendirmek için 6 Dakika Yürüme Testi (DYT) kullanıldı. Çünkü 6DYT, okul öncesi çocuklarda kardiorespiratuar uygunluğu değerlendiren mekik koşu testiyle benzerlik göstermektedir. Hatta tek araştırmacıyla, video sinyali, teyp kullanmaksızın yapılabildiği ve daha yaygın kullanımından dolayı avantaja sahiptir (Laboratories, 2002).

6DYT kişinin kendi yürüme hızıyla fonksiyonel egzersiz kapasitesini submaksimal seviyede değerlendiren ucuz, ekipman gerektirmeyen, pratik uygulanabilen çok uygun bir yöntemdir (Geiger et al., 2007; Lammers, Hislop, Flynn, \& Haworth, 2007; Li et al., 2007). Erişkinlerde kullanılmak üzere standart protokolü belirtilen bu yöntemin (Laboratories, 2002) modifiye edilerek sağlıklı çocuk ve adölosanlarda da geçerlik çalışmaları yapılmış ve standart değerleri belirtilmiştir (Geiger et al., 2007; Lammers et al., 2007; Li et al., 2007). Bu teste göre çocukların 6 dakika boyunca düz, sert bir yüzeyde, koşmadan olabildiğince hızlı yürümeleri istendi ve bunun için sözel olarak teşvik edildi (Geiger et al., 2007; Lammers et al., 2007). Test uzunluk mesafesi, yapılan çalışmalarda $20-50 \mathrm{~m}$ arasında değişmekle birlikte (Laboratories, 2002) pediatrik populasyonda $15-20 \mathrm{~m}$ olarak kullanılması tavsiye edilmektedir (de Groot \& Takken, 2011). Çocukları yönlendirmek için ölçülen mesafe bant şeritle işaretlendi ve her iki ucuna koni yerleştirildi. Yürünen toplam mesafe " $m$ " olarak kaydedildi (Laboratories, 2002).

\subsubsection{3. Üst ekstremite kas kuvveti}

Üst gövde ve üst ekstremite kas kuvvetini değerlendirmek için dijital $0.5 \mathrm{~kg}$ hassasiyeti sahip, $0-100 \mathrm{~kg}$ arasında ölçüm yapabilen Takei marka el dinamometresi kullanıldı. El kavrama kuvveti testi, üst ekstremite izometrik kas kuvvetini değerlendirmektedir. Dinamometrenin kabzası çocuklar için optimal kavrama derecesi olan $4 \mathrm{~cm}$ olarak ayarland. Ölçüm yapılırken çocuklar ayakta dirseği bükmeden ve vücuda temas etmeden dinamometreyi en az 2 veya 3 saniye sürekli olacak şekilde, sıkabildiği kadar sıkması istendi. Kısa bir aradan sonra tekrar edilip iki denemeden en iyi değer kaydedildi. Her iki elde ayrı ayrı bu ölçüm tekrarlandı ve iki elin kuvvetinin ortalamas1 "kg" olarak kaydedildi (CadenasSanchez et al., 2016; Martinez-Tellez et al., 2016; SanchezDelgado et al., 2015).

\subsubsection{Alt ekstremite kas kuvveti}

Alt gövde ve alt ekstremite kas kuvvetini değerlendirmek için durarak uzun atlama testi kullanıldı. Çocukların patlayıcı kuvvetini ölçen bu test; sert, kaygan olmayan bir zeminde, ayaklar omuz genişliğinde birbirinden ayrı, başlama çizgisinin gerisinden yapabildiği kadar çift ayakla uzağa zıplayarak düşmeden ayakta kalabildiği mesafeyi içermektedir. Test kısa aralıklarla $3 \mathrm{kez}$ denendikten sonra çocuğun ulaştı̆̆ en uzak mesafe "cm" olarak kaydedildi (Cadenas-Sanchez et al., 2016; Martinez-Tellez et al., 2016). Çocuklara kolaylık olması için başlama çizgisi işaretlenerek atlama mesafesi şerit bantla yapıştırılıp $\mathrm{cm}$ olarak ölçeklendirildi (Cadenas-Sanchez et al., 2016).

\subsubsection{Hiz ve çeviklik testi}

Hız ve çevikliği değerlendirmek için $4 \times 10 \mathrm{~m}$ koşu testi kullanıld. Test kaygan olmayan bir zeminde toplam $40 \mathrm{~m}$ olmak üzere $10 \mathrm{~m}$ arayla çizilmiş paralel iki çizgi arasında yapılabildiği kadar hızlı ileri-geri koşup dönmeyi içermektedir. Çocuk her turda iki ayağıyla birlikte bitiş çizgilerini geçip araştırmacının eline dokunmak zorundadır. Çocuklar testi kısa bir dinlenmeden sonra ikinci kez denedi. Her iki denemeden daha iyi sonuç alınan skor (minimum) "sn" olarak kaydedildi (Cadenas-Sanchez et al., 2016; Martinez-Tellez et al., 2016). Çocuklara kolaylık olması için paralel çizgilerin bir ucuna araştırmacı diğer ucuna çocuğun ailesi yerleştirilerek test esnasında araştırmacı ve ailenin eline dokunmasi istendi (Cadenas-Sanchez et al., 2016).

\subsubsection{Denge testi}

Dengeyi değerlendirmek için tek bacak üzerinde durma testi kullanıldı. Statik dengeyi değerlendiren bu teste göre çocuk, tek bacak üzerinde dururken diğer bacağı dizden bükülü olacak şekilde yapabildiği kadar bu pozisyonda dengesini devam ettirmeyi içermektedir. Serbest bacağını zeminden kaldırdıktan hemen sonra kronomotre aktive edildi. Dengeyi devam ettirebilmek için kollarını kullanmasına izin verildi. Eğer çocuk dengesini devam ettiremezse (örneğin bir yere tutunma, dengede durduğu ayağı hareket ettirme gibi durumlarda) test bitirildi. Çocukların tek bacak üzerinde durma testi her iki ayak için bir kez deneme yapıldıktan sonra her iki ayağın ortalamaları alınarak "sn" cinsinden kaydedildi (Cadenas-Sanchez et al., 2016; Martinez-Tellez et al., 2016).

\section{3. İstatistiksel analiz}

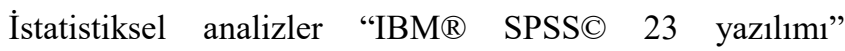
kullanılarak yapıldı. Sayısal değişkenlerin normal dağılıma uygunluğu görsel (histogram ve olasıllk grafikleri) ve analitik yöntemler (Kolmogorov-Smirnov/Shapiro Wilk testleri) kullanılarak yapıldı. Değişkenler arası ilişkiler için en az biri normal dağılmayan ya da ordinal ise korelasyon katsayıları ve istatistiksel anlamlılıklar Spearman testi ile hesapland. Korelasyonun derecesi korelasyon katsayısına göre 0.05-0.4 arası düşük derecede korelasyon, 0.4-0.7 orta derecede korelasyon ve 0.7-1.0 aras1 yüksek derecede korelasyon şeklinde yorumlandı (Hayran \& Hayran, 2011). Karşılaştırmalarda normal dağılım gösteren sayısal değişkenler için tanımlayıcı istatistikler ortalama ve standart sapma ile verilirken, normal dağılım göstermeyen sayısal 
değişkenlerin tanımlayıcı istatistikleri ortanca ve çeyrekler arası değer ile ifade edildi. Normal dağılım gösteren üç grubun karşılaştırılmasında Tek Yönlü Varyans Analizi (ANOVA) kullanılırken, en az biri normal dağılım göstermeyen üç grubun karşılaştırılmasında Kruskal-Wallis Testi kullanıldı. Normal dağılmayan üç grubun Post-Hoc analizleri Bonferonni düzeltmesi sonrası Mann-Whitney U testi kullanılarak yapıldı. İstatistiksel olarak anlamlılık düzeyi; $\mathrm{p}<0,05$ olarak kabul edildi.

\section{Bulgular}

Çalışmaya alınan çocukların verilerine ait tanımlayıcı özellikleri Tablo 1'de verilmiştir.

Tablo 1. Çalışmaya Alınan Çocukların Verilerine Ait Tanımlayıcı Özellikleri

\begin{tabular}{|c|c|c|}
\hline & $\begin{array}{l}\text { Ort } \pm \text { SS } \\
(\mathrm{n}=212)\end{array}$ & Min-Max \\
\hline $\begin{array}{l}\text { Yaş (ay) } \\
\text {. }\end{array}$ & $62 \pm 7$ & 44-75 \\
\hline Kilo (kg) & $19.3 \pm 3$ & $13.2-32.5$ \\
\hline Boy $(\mathrm{cm})$ & $109 \pm 6$ & $92-123$ \\
\hline$\overline{\mathrm{VKI}}\left(\mathrm{kg} / \mathrm{m}^{2}\right)$ & $16.2 \pm 1.7$ & $12.7-22.5$ \\
\hline Kavrama kuvveti $(\mathrm{kg})$ & $7 \pm 1.5$ & $5-14.2$ \\
\hline 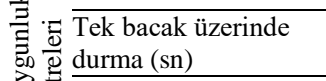 & $18.6 \pm 14.3$ & $3.5-94$ \\
\hline 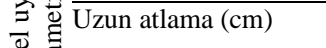 & $82 \pm 17$ & $37-120$ \\
\hline 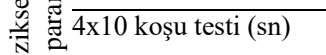 & $17.55 \pm 2$ & $14-25$ \\
\hline 6DYT (m) & $396 \pm 52$ & $290-560$ \\
\hline Okuldaki dönem sayısı & $3 \pm 1$ & $1-8$ \\
\hline$\overline{\text { Evdeki çocuk sayısı }}$ & $3 \pm 1$ & $1-8$ \\
\hline
\end{tabular}

VKİ: Vücut Kütle İndeksi, DYT: Dakika Yürüme Testi, n: Kişi sayısı, Ort: Ortalama, SS: standart sapma

Çocukların doğum ağırlığına göre fiziksel uygunluk parametrelerinin karşılaştırılması Tablo 2'de verilmiştir. Bu tabloya göre;

Çocuklar doğum ağırlığına göre fiziksel uygunluk parametreleri açısından karşılaştırıldığında anlamlı bir fark bulunmadi $(\mathrm{p}>0.05)$.

Tablo 2. Çocukların Doğum Ağırlığına Göre Fiziksel Uygunluk Parametrelerinin Karşılaştırılması

\begin{tabular}{|c|c|c|c|c|c|}
\hline & \multicolumn{3}{|c|}{ Doğum Ağırlığ1 } & \multirow[b]{2}{*}{$\mathrm{p}$} \\
\hline & & $\begin{array}{c}\text { Düşük } \\
n=19 \\
\text { Ort } \pm S S\end{array}$ & $\begin{array}{c}\text { Normal } \\
\mathrm{n}=185 \\
\text { Ort } \pm \mathrm{SS}\end{array}$ & $\begin{array}{c}\text { Yüksek } \\
n=8 \\
\text { Ort } \pm S S\end{array}$ & \\
\hline \multirow{6}{*}{ 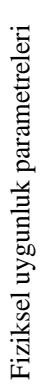 } & $\begin{array}{l}\text { Uzun atlama } \\
(\mathrm{cm})\end{array}$ & $81 \pm 21$ & $82 \pm 16$ & $81 \pm 14$ & $0.949 *$ \\
\hline & & $\begin{array}{c}\text { Ortanca } \\
\text { (IQR) }\end{array}$ & $\begin{array}{c}\text { Ortanca } \\
\text { (IQR) }\end{array}$ & $\begin{array}{c}\text { Ortanca } \\
\text { (IQR) }\end{array}$ & \\
\hline & $\begin{array}{l}\text { Kavrama } \\
\text { kuvveti (kg) }\end{array}$ & $6.8(1.4)$ & $6.7(1.8)$ & $6.2(3.8)$ & $0.971 * *$ \\
\hline & $\begin{array}{l}\text { Tek bacak } \\
\text { üzerinde } \\
\text { denge(sn) }\end{array}$ & $10(9)$ & $15(16)$ & $10(12)$ & $0.142 * *$ \\
\hline & $\begin{array}{l}4 \times 10 \text { koşu } \\
\text { testi }(\mathrm{sn})\end{array}$ & $18(2)$ & $17(2)$ & $18(2.7)$ & $0.076^{* *}$ \\
\hline & 6DYT (m) & $390(65)$ & $390(70)$ & $378(63)$ & $0.641 * *$ \\
\hline
\end{tabular}

*Tek Yönlü Varyans Analizi, **Kruskal Wallis, p > 0.05, DYT: dakika yürüme testi, IQR: İnter Quartile Range, Ort: Ortalama, SS: standart sapma, n: Kişi sayısı
Çocukların fiziksel uygunluk parametreleriyle okuldaki dönem sayısı arasındaki ilişki incelenmiş olup Tablo 3'te verilmiştir. Bu tabloya göre;

Fiziksel uygunluk parametreleri olan kavrama kuvveti, tek bacak üzerinde denge, uzun atlama, 6DYT ile okuldaki dönem sayısı arasında pozitif yönde düşük düzeyde anlamlı bir ilişki bulunurken; 4x10 koşu testiyle negatif yönde düşük düzeyde anlamlı bir ilişki bulundu $(\mathrm{p}<0.05)$.

Tablo 3. Çocukların Fiziksel Uygunluk Parametreleriyle Okuldaki Dönem Sayısı Arasındaki İlişki

\begin{tabular}{lcccccc}
\hline & & $\begin{array}{c}\text { Kavrama } \\
\text { kuvveti }\end{array}$ & $\begin{array}{c}\text { Tek bacak } \\
\text { üzerinde } \\
\text { denge }\end{array}$ & $\begin{array}{c}\text { Uzun } \\
\text { atlama }\end{array}$ & $\begin{array}{c}4 \times 10 \text { koşu } \\
\text { testi }\end{array}$ & 6DYT \\
\hline Okuldaki & $\mathrm{r}$ & 0.170 & 0.141 & 0.180 & -0.200 & 0.212 \\
\cline { 2 - 7 } dönem sayısı & $\mathrm{p}$ & 0.013 & 0.040 & 0.009 & 0.003 & 0.002 \\
\hline Spearman korelasyon testi, p < 0.05, DYT: dakika yürüme testi. &
\end{tabular}

Ailelerin gelir düzeyine göre fiziksel uygunluk parametreleri ve evdeki çocuk sayısı karşılaştırılması Tablo 4'de verilmiştir. Bu tabloya göre;

Ailelerin gelir düzeyine göre evdeki çocuk sayısı açısından anlamlı fark bulunurken $(\mathrm{p}<0.05)$; diğer değişkenler arasında anlamlı bir fark bulunmadı $(\mathrm{p}>0.05)$.

Tablo 4. Ailelerin Gelir Düzeyine Göre Fiziksel Uygunluk Parametreleri ve Evdeki Çocuk Sayısının Karşılaştırılması Ailenin Gelir Düzeyi

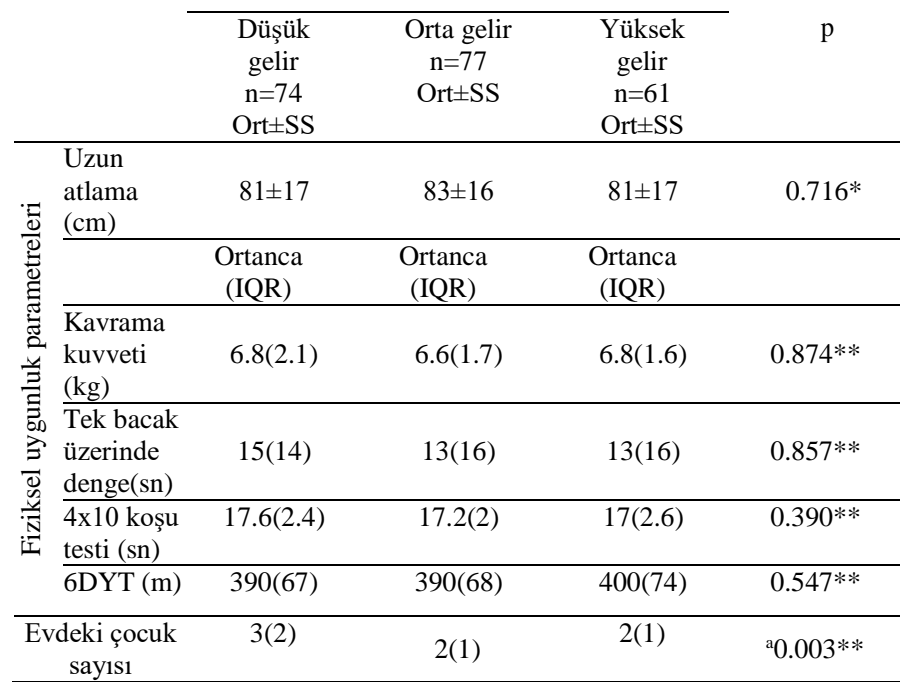

*Tek Yönlü Varyans Analizi, **Kruskal Wallis, p < 0.05, DYT: dakika yürüme testi, IQR: İnter Quartile Range, n: Kişi sayısı, Ort: Ortalama, SS: standart sapma a:Bonferonni düzeltmesi sonrası düşük gelir ile yüksek gelir arasında istatistiksel olarak fark vardır.

\section{Tartışma}

Doğum ağırlığının uzun dönemde pek çok risk faktörünün yanı sıra (Singhal, Wells, Cole, Fewtrell, \& Lucas, 2003); fiziksel uygunluk üzerine etkisinin araştırıldığı çalışmalara da rastlanmaktadır (Moura-Dos-Santos et al., 2013). Çok düşük doğum ağırlığına sahip okul dönemi çocukların normal doğum ağırlığına sahip çocuklara göre daha düşük motor performans sergiledikleri ifade edilmektedir (Marlow, Roberts, \& Cooke, 1993). Burns ve ark. (Burns et al., 2009) çok düşük doğum ağırlığına sahip 11-13 yaş arası 54 çocuk ve benzer yaştaki 55 normal doğum ağırlığına sahip çocukların fiziksel uygunluklarını "Çocuklar için Hareket Değerlendirme Test Bataryası” kullanılarak karşılaştırmışlar ve anlamlı derecede çok düşük doğum ağırlığına sahip 
çocukların fiziksel uygunluklarının daha düşük olduğunu tespit etmişler. Moura Dos Santos ve ark. (Moura-DosSantos et al., 2013) tarafindan FITNESSGRAM ve European Test of Physical Fitness (EUROFIT) test bataryalarının standartlarına göre yaptıkları başka bir çalışmada, yaşları 710 yıl arasında değişen düşük doğum ağırlığına sahip $(<2500$ g) 100 çocuk ve 256 normal doğum ağırlığına (>3.000 g ve $<3.999 \mathrm{~g})$ sahip çocukların fiziksel uygunlukları karşılaştırılmış ve düşük doğum ağırlığına sahip çocukların daha düşük kavrama kuvveti ve $20 \mathrm{~m}$ koşma hızına sahip oldukları ancak; daha yüksek kardiovasküler uygunluğa sahip oldukları tespit edilmiştir. Aynı çalışmada durarak uzun atlama, otur-uzan ve 4x4 m mekik koșusu test skorları açısından istatistiksel bir fark bulunamamıştır. Ayrıca statik denge açısından çok düşük doğum ağırlığına sahip çocukların normal doğum ağırlığına sahip çocuklardan anlamlı derecede daha düşük olduğu belirtilmektedir (Burns et al., 2009; Powls, Botting, Cooke, \& Marlow, 1995). Özen (ÖZEN, 2014) yaşları 8-10 yıl arasında değişen 60 düşük doğum ağırlıklı, 60 yüksek doğum ağırlıklı ve 60 normal doğum ağırlığına sahip çocuklarda EUROFIT test bataryası kullanarak fiziksel uygunluklarını karşılaştırdığı çalışmada flamingo denge, durarak uzun atlama, el kavrama kuvveti, 30 sn mekik, bükülü kol asılma ve $5 \times 10$ m mekik koşusu parametrelerinin hiç birinde anlamlı bir fark bulamamıştır. Normal doğum ağırlığına sahip çocukların, düşük doğum ağırlığı ve yüksek doğum ağırlığına sahip çocuklardan klinik olarak fark olmasına rağmen istatistiksel olarak bir fark bulunamamasının nedeni, düşük doğum ağırlığına ve yüksek doğum ağırlığına sahip çocukların doğum ağırlığının normal doğum ağırlığına sahip çocuklara yakın olması aradaki farkı kapatmış olabilir. Çünkü yukarıdaki fark çıkan çalışmaların pek çoğu çok düşük doğum ağırlığına sahip çocuklarda yapıldığı görülmektedir. Oysa Ö̈zen'in çalışmasındaki en küçük ortalama doğum ağırlığı 2113 gr'dır. Çalışmamız okul öncesi çocukları doğum ağırlığına göre fiziksel uygunluğunu karşılaştıran ilk çalışma olmasına rağmen; fiziksel uygunluk parametreleri karşılaştırıldı ğında istatistiksel olarak herhangi bir fark bulunamamıştır. Bunun nedeni olarak Özen'in çalışmasına benzer olarak gruplardaki örneklem sayısının yetersizliği ve ortalama ağıllkların birbirine yakınlığı olabilir. $\mathrm{Bu}$ yaş aralığına sahip daha düşük doğum ağırlığındaki çocuklar üzerinde araştırmanın yapılması açıktır.

Okul öncesi çocuklarda temel beceriler olan koşma, sıçrama, atlama gibi fiziksel aktiviteler çocukların eğitim ve öğrenme deneyimlerinin bir parçasıdır. $\mathrm{Bu}$ dönemde öğrenilen beceriler, çocuğun sonraki aktiviteleri için temel oluşturarak ileriki hayatları için kalıcı olmaktadır. Böylece bu çocuklarda temel beceri hareketlerine yönelik tecrübe etme olanaklarının yetersiz olması ya da kısıtlanması çocukların motor performanslarının olumsuz olarak etkilenmesine sebep olmaktadır. (Kerkez, 2012). Çocuklara bu açıdan en uygun ortamlardan birisini sağlayan, okul ortamıdır. Çünkü okul ortamı öğrenme/öğretme etkinliklerinin meydana geldiği, çocukların birbirleriyle iletişim/etkileşim kurduğu çevrenin yanı sıra (Karaküçük, 2008); hareket alanının artması, daha fazla keşif ve öğrenmesini etkileyerek daha hareketli bir ortam oluşturmaktadır (Kaçan, Halmatov, \& Kartaltepe, 2017). Okul öncesi çocuklarda okul ortamının çocukların gelişim parametrelerini (Bayoglu, Bakar, Kutlu, Karabulut, \& Anlar, 2007), okul dönemi çocukların fiziksel uygunluklarını, öğrenme yetenekleri ve sosyal yönleriyle ilişkisini ortaya koyan çalışmalar bulunmaktadır (Christodoulos et al., 2006; Delidou et al., 2016). Literatürde okul öncesi çocukların okulda geçirdikleri dönem ile fiziksel uygunlukları arasında ilişkiyi araştıran çalışmaya rastlanılmamıştır. Çalışmamızda okul öncesi çocuklarda fiziksel uygunluğun tüm parametreleriyle okuldaki dönem sayısı arasında istatistiksel olarak ilişki saptanmıştır. Böylece okul öncesi çocukların okulda geçirdikleri dönem artıkça fiziksel uygunlukları da artmaktadır. Bu sonuçtan hareketle bu çocukların temel öğrenim ve becerileri gelişmesinin yanı sıra; fiziksel uygunluklarını da olumlu yönde etkilemesi açısından anaokuluna bir an önce başlamanın faydası ortaya çıkmış bulunmaktadır. Sadece aile ve öğretmenlerin bu konuya önem vermesiyle birlikte, devletin de daha sağlıklı nesiller için anaokulu çağına gelmiş çocukların okula kaydının yapılmasını yasal olarak zorunlu kılması gerekmektedir.

Sosyo-ekonomik yapının hem çocuklarda hem de yetişkinlerde fiziksel uygunluk ve spor performans seviyeleri üzerinde etkisi olan önemli bir faktördür (Goslin \& Burden, 1986; Malina et al., 2004). Konu ile ilgili okul dönemi ve adölesan çocuklarda yapılan çalışmalara bakıldığında bazı çalışmalar orta ve yüksek sosyo-ekonomik düzeye sahip ailelerin çocuklarına düşük olan ailelere oranla daha iyi beslenme, sağlık hizmeti ve çocuk bakımı imkanları verebildikleri için (Bernink, Erich, Peltenburg, Zonderland, \& Huisveld, 1983) fiziksel uygunluklarının daha iyi olduğunu belirtirken (Goslin \& Burden, 1986; Pérez, D’Angelo, \& Zabala, 1991); bazı çalışmalarda ise düşük sosyo-ekonomik düzeye sahip çocukların fiziksel uygunluklarının daha iyi olduklarını belirtse de (Tekelioğlu, 1999), yüksek sosyoekonomik düzeye sahip çocukların sportif aktivitelere katılımlarının daha yüksek olduğu sonucu da ifade edilmektedir (Pérez et al., 1991). Oğuz (Oğuz, 1998) farklı sosyo-ekonomik düzeye sahip okul dönemi çocuklarda yaptığı bir çalışmada sosyo-ekonomik düzeyi yüksek çocukların patlayıcı güç ve hız gerektiren motor aktivitelerde daha yüksek, düşük sosyo-ekonomik düzeyde olanların ise denge, üst ekstremite kas kuvveti ve dayanıklılık testlerinde daha yüksek skorlara sahip olduklarını bulmuştur. Güler ve ark. (Güler \& Günay, 2004) 8-10 yaş arası çocuklarda AAHPERD (American Alliance for Health, Physical Education, Recreation and Dance) fiziksel uygunluk test bataryasının sosyo-ekonomik düzey ile ilişkisini araştırdıkları bir çalışmada sosyo-ekonomik düzeyin çocuklarda fiziksel uygunluğu etkilediği bulunmuş ve yüksek sosyo-ekonomik düzeye sahip çocukların mekik kuvvet testinin daha yüksek, düşük sosyo-ekonomik düzeye sahip olanların ise barfiks kuvveti ve kardiyovasküler dayanıklılık testleri yüksek bulunmuştur. Çalışmamızda okul öncesi 4-6 yaş arası çocukların ailelerinin gelir düzeyine göre çocukların fiziksel uygunlukları karşılaştırıldığında herhangi bir fark bulunamamıştır. Bunun nedenleri arasından birisi çocukların anaokuluna devam etmeleri fiziksel uygunları arasındaki farkı etkilemiş olabilir. $\mathrm{Bu}$ yaş aralığındaki sosyo-ekonomik yapıya göre okula giden ve gitmeyen çocuklarda fiziksel uygunluk karşılaştırması araştırmaya açık bir durumdur. 


\section{Sonuç ve Öneriler}

Okul öncesi dönemdeki çocukların okulda geçirdikleri dönem sayısı artıkça fiziksel uygunlukları da artmaktadır. Bu çocuklarda temel öğrenim ve beceri gelişiminin yanı sıra; fiziksel uygunluklarını da olumlu yönde etkilemesi açısından 4 yaşına gelen çocukların anaokuluna bir an önce başlatılması, hatta bunun bir devlet politikası haline getirilmesi önerilmektedir. Gelir düzeyi düşük olan ailelerdeki çocuk sayısı daha fazla bulunmaktadır. Aile eğitimi ve nüfus planlaması adına gerekli danışmanlık hizmeti verilmeli var olan danışmanlık hizmeti ise bu ailelere yönelik artırılmalıdır.

\section{Kaynakça}

Bayoglu, B. U., Bakar, E. E., Kutlu, M., Karabulut, E., \& Anlar, B. (2007). Can preschool developmental screening identify children at risk for school problems? Early Human Development, 83(9), 613-617.

Bernink, M., Erich, W., Peltenburg, A., Zonderland, M., \& Huisveld, I. (1983). Height, body composition, biological maturation and training in relation to socio-economic status in girl gymnasts, swimmers, and controls. Growth, 47(1), 1-12.

Burns, Y. R., Danks, M., O'callaghan, M. J., Gray, P. H., Cooper, D., Poulsen, L., \& Watter, P. (2009). Motor coordination difficulties and physical fitness of extremely-low-birthweight children. Developmental Medicine \& Child Neurology, 51(2), 136-142.

Cadenas-Sanchez, C., Martinez-Tellez, B., SanchezDelgado, G., Mora-Gonzalez, J., Castro-Pinero, J., Lof, M., . . . Ortega, F. B. (2016). Assessing physical fitness in preschool children: Feasibility, reliability and practical recommendations for the PREFIT battery. Journal of Science and Medicine in Sport, 19(11), 910-915. doi:10.1016/j.jsams.2016.02.003

Christodoulos, A. D., Flouris, A. D., \& Tokmakidis, S. P. (2006). Obesity and physical fitness of pre-adolescent children during the academic year and the summer period: effects of organized physical activity. Journal of Child Health Care, 10(3), 199-212.

de Groot, J. F., \& Takken, T. (2011). The six-minute walk test in paediatric populations. Journal of physiotherapy, 57(2), 128.

de Rezende, L. F. M., Lopes, M. R., Rey-Lopez, J. P., Matsudo, V. K. R., \& Luiz, O. D. (2014). Sedentary Behavior and Health Outcomes: An Overview of Systematic Reviews. Plos One, 9(8). doi:ARTN e10562010.1371/journal.pone.0105620

Delidou, E., Matsouka, O., \& Nikolaidis, C. (2016). Influence of school playground size and equipment on the physical activity of students during recess. European Physical Education Review, 22(2), 215-224.

Geiger, R., Strasak, A., Treml, B., Gasser, K., Kleinsasser, A., Fischer, V., . . . Stein, J. I. (2007). Six-minute walk test in children and adolescents. The Journal of pediatrics, 150(4), 395-399. e392.
Goslin, B. R., \& Burden, S. B. (1986). Physical fitness of South African school children. The Journal of sports medicine and physical fitness, 26(2), 128-136.

Güler, D., \& Günay, M. (2004). Çocuklarda SosyoEkonomik Düzeyin Fiziksel Uygunluğa Etkisinin AAHPERD Fiziksel Uygunluk Test Bataryasi İle Değerlendirilmesi. Ahi Evran Üniversitesi Kırşehir Eğitim Fakültesi Dergisi, 5(1).

Hayran, M., \& Hayran, M. (2011). Sağl1k Araştırmaları İçin Temel İstatistik (1. Basım). Art Ofset Matbaacıllk Yayıncılık Organizasyon. Ankara. Sayfa, 95.

Health, U. D. o., \& Services, H. (2008). Physical activity guidelines advisory committee. Washington DC: US Department of Health and Human Services.

Kaçan, M. O., Halmatov, M., \& Kartaltepe, O. (2017). Okul öncesi eğitim kurumları bahçelerinin incelenmesi. Erken Çocukluk Çalışmaları Dergisi, 1(1), 60-70.

Karaküçük, S. A. (2008). Okul Öncesi Eğitim Kurumlarında Fiziksel/Mekansal koşulların İncelenmesi. Sosyal Bilimler Dergisi/Journal of Social Sciences, 32(2).

Kelly, L. E. (2000). Patterns of physical activity in 9-10year-old American children as measured by heart rate monitoring. Pediatric exercise science, 12(1), 101-110.

Kerkez, F. İ. (2012). Sağlıklı Büyüme İçin Okul Öncesi Dönemdeki Çocuklarda Hareket ve Fiziksel Aktivite. Spor Bilimleri Dergisi, 23(1), 34-42.

Kolimechkov, S. (2017). Physical Fitness Assessment in Children and Adolescents: A Systematic Review. European Journal of Physical Education and Sport Science.

Laboratories, A. C. o. P. S. f. C. P. F. (2002). ATS statement: guidelines for the six-minute walk test. Am J Respir Crit Care Med, 166, 111-117.

Lammers, A. E., Hislop, A. A., Flynn, Y., \& Haworth, S. G. (2007). The six-minute walk test: Normal values for children of 4-11 years of age. Archives of disease in childhood.

Li, A. M., Yin, J., Au, J. T., So, H. K., Tsang, T., Wong, E., . . . Ng, P. C. (2007). Standard reference for the sixminute-walk test in healthy children aged 7 to 16 years. American Journal of Respiratory and Critical Care Medicine, 176(2), 174-180.

Lopes, V. P., Rodrigues, L. P., Maia, J. A. R., \& Malina, R. M. (2011). Motor coordination as predictor of physical activity in childhood. Scandinavian Journal of Medicine \& Science in Sports, 21(5), 663-669. doi:10.1111/j.16000838.2009.01027.x

Malina, R. M., Bouchard, C., \& Bar-Or, O. (2004). Growth, maturation, and physical activity: Human kinetics.

Marlow, N., Roberts, L., \& Cooke, R. (1993). Outcome at 8 years for children with birth weights of $1250 \mathrm{~g}$ or less. Archives of disease in childhood, 68(3 Spec No), 286290.

Martinez-Tellez, B., Sanchez-Delgado, G., CadenasSanchez, C., Mora-Gonzalez, J., Martin-Matillas, M., 
Lof, M., . . . Ruiz, J. R. (2016). Health-related physical fitness is associated with total and central body fat in preschool children aged 3 to 5 years. Pediatric Obesity, 11(6), 468-474. doi:10.1111/ijpo.12088

Moura-Dos-Santos, M., Wellington-Barros, J., BritoAlmeida, M., Manhães-de-Castro, R., Maia, J., \& Góis Leandro, C. (2013). Permanent deficits in handgrip strength and running speed performance in low birth weight children. American Journal of Human Biology, 25(1), 58-62.

Oğuz, H. (1998). Bursa ilinde farklı sosyo-ekonomik düzeye sahip ailelerin 8,9 ve 10 yaş grubu çocukların fiziksel performans ve antropometrik özelliklerinin incelenmesi. Yüksek Lisans Tezi, Uludă̆ Üniversitesi Sosyal Bilimler Enstitüsü, Bursa.

Ortega, F. B., Cadenas-Sanchez, C., Sanchez-Delgado, G., Mora-Gonzalez, J., Martinez-Tellez, B., Artero, E. G., . . . Ruiz, J. R. (2015). Systematic Review and Proposal of a Field-Based Physical Fitness-Test Battery in Preschool Children: The PREFIT Battery. Sports medicine, 45(4), 533-555. doi:10.1007/s40279-014-0281-8

Ortega, F. B., Ruiz, J. R., Castillo, M. J., \& Sjostrom, M. (2008). Physical fitness in childhood and adolescence: a powerful marker of health. Int J Obes (Lond), 32(1), 111. doi:10.1038/sj.ijo.0803774

Özen, G. (2014). 8-10 Yaş Çocuklarda Doğum Ağırlı̆̆ının Bazl Fiziksel Uygunluk Parametreleri Üzerine Etkisi İnönü Üniversitesi, Malatya.

Pérez, G. E. N., D’Angelo, C. P., \& Zabala, R. D. (1991). Physical Fitness in Children and Adolescents from Differing Socioeconomic Strata Human growth, physical fitness and nutrition (Vol. 31, pp. 80-98): Karger Publishers.

Powls, A., Botting, N., Cooke, R. W., \& Marlow, N. (1995). Motor impairment in children 12 to 13 years old with a birthweight of less than $1250 \mathrm{~g}$. Archives of Disease in Childhood-Fetal and Neonatal Edition, 73(2), F62-F66.

Sanchez-Delgado, G., Cadenas-Sanchez, C., MoraGonzalez, J., Martinez-Tellez, B., Chillón, P., Löf, M., . . . Ruiz, J. (2015). Assessment of handgrip strength in preschool children aged 3 to 5 years. Journal of Hand Surgery (European Volume), 40(9), 966-972.

Singhal, A., Wells, J., Cole, T. J., Fewtrell, M., \& Lucas, A. (2003). Programming of lean body mass: a link between birth weight, obesity, and cardiovascular disease? The American journal of clinical nutrition, 77(3), 726-730.

Smith, J. J., Eather, N., Morgan, P. J., Plotnikoff, R. C., Faigenbaum, A. D., \& Lubans, D. R. (2014). The health benefits of muscular fitness for children and adolescents: a systematic review and meta-analysis. Sports medicine, 44(9), 1209-1223.

Tekelioğlu, A. (1999). Physical Fitness of Girls and Boys Aged 11-13 Years Attending to Goverment School and Private School. Doktora Dissertation, GÜ Institute of Medical Sciences, Ankara(s 7), 71.

Thompson, P. D., Arena, R., Riebe, D., \& Pescatello, L. S. (2013). ACSM's New Preparticipation Health Screening Recommendations from ACSM's Guidelines for Exercise Testing and Prescription, Ninth Edition. Current Sports Medicine Reports, 12(4), 215-217. doi:DOI 10.1249/JSR.0b013e31829a68cf 
